\title{
Article \\ Exploring Association between Self-Reported Financial Status and Economic Preferences Using Experimental Data
}

\author{
Calvin Mudzingiri $\left.{ }^{1}{ }^{(}\right)$, Sevias Guvuriro ${ }^{2, *} \mathbb{\infty}$ and Charity Gomo ${ }^{1}$ \\ 1 Department of Economics \& Finance, Qwaqwa Campus, University of the Free State (UFS) \\ Phuthaditjhaba 9866, South Africa; mudzingiric@ufs.ac.za (C.M.); gomoc@ufs.ac.za (C.G.) \\ 2 Department of Economics \& Finance, University of the Free State (UFS), Bloemfontein 9300, South Africa \\ * Correspondence: guvuriros@ufs.ac.za; Tel.: +27-51-401-9196
}

Citation: Mudzingiri, Calvin, Sevias Guvuriro, and Charity Gomo. 2021. Exploring Association between Self-Reported Financial Status and Economic Preferences Using Experimental Data. Journal of Risk and Financial Management 14: 243. https://doi.org/10.3390/jrfm14060243

Academic Editor: Thanasis Stengos

Received: 19 March 2021

Accepted: 19 May 2021

Published: 31 May 2021

Publisher's Note: MDPI stays neutral with regard to jurisdictional claims in published maps and institutional affiliations.

Copyright: (c) 2021 by the authors. Licensee MDPI, Basel, Switzerland. This article is an open access article distributed under the terms and conditions of the Creative Commons Attribution (CC BY) license (https:// creativecommons.org/licenses/by/ $4.0 /)$.

\begin{abstract}
Research on economic behaviour of individuals in different financial statuses such as being in a good financial standing or in a threatening financial situation are inconclusive. Some evidence suggest that the culture of poverty may shape and dominate the economic preferences of those who are poor and even make them being prone to trembling and making mistakes thereby making decisions that do not maximize their utility. Other evidence suggest that the poor exercise extra caution and fail to maximize utility. This study investigates the association between selfreported financial status and economic preferences in a developing country setting using data from an incentivized experiment and a survey. Extended random effects panel probit regression models are employed as an analytical strategy. The study established a positive association between being financially broke or very broke and being risk averse. In addition, a positive association is found between being financially 'very broke' and impatient. Such findings illustrate the importance of psychology of poverty in economic preferences and in decision-making in general, even as poverty is temporary as represented by self-reported financial status.
\end{abstract}

Keywords: culture of poverty; financial decision-making; financial status; risk preferences; time preferences; financially very broke

\section{Introduction}

People make decisions that involve risk and time preferences in their day-to-day life. The decisions made are across spectrum of activities and in most cases with some degree of uncertainty. Day-to-day decision-making processes also involve thinking on the margins (Bangs 2009), when additional benefits are compared to additional costs. An emerging line of thinking in the economic preferences domain relates to the economic and social conditions under which people make economic decisions. The current study attempts to contribute to this emerging body of literature by exploring the association between financial status (a temporary measure of poverty) and economic preferences. Economic and social conditions influence the choices at stake and marginal sizes differently, and for different people. Haushofer and Fehr (2014), for instance, stated that economic and social conditions that poor people live in influence their discount rates and risk taking behaviours. This suggests that the differences in risk and time preferences between the poor and the non-poor is not intrinsic. Further, it suggests that preferences are not always permanent but are malleable (Alan et al. 2020). Ravallion (2012) proposed that relevant data in a given context, inclusive of people's preferences, must inform actions to fight social ills such as poverty.

In order to obtain better measurements of risk and time preferences, economists have turned to experiments, among other methods. The recent past has seen growth in experimental economics literature that focuses on the role of risk preferences (Andreoni et al. 2020) on life outcomes such as labour outcomes (Bertrand 2011); holding stocks, occupational choices and smoking (Dohmen et al. 2011); investment outcomes (Insler et al. 
2016), and socio-economic status or interventions (Sutter et al. 2019). A similar trend can be observed for time preferences and Cohen et al. (2020) provide a detailed survey categorising between studies that use financial flows 'money earlier or later' decisions and those that use time-dated consumption or efforts.

The quest to establish the association between financial status (an economic condition) and economic preferences is driven by the zeal to advance knowledge on the views to explain decision-making processes identified as rational choice, pathological, and bounded rationality (Bertrand et al. 2004; Mullainathan and Shafir 2013). While rational choices assume that individuals perfectly adapt to the prevailing economic environments and make optimal decisions that are commensurate with conditions at stake, the pathological view argues that there are psychological pathologies that characterise circumstances of scarcity (Mullainathan and Shafir 2013). Due to the psychological pathologies, the culture of poverty may shape and dominate the preferences of those who are poor and even make them prone to making more mistakes and make decisions that do not maximise their utility. However, boundedness (i.e., bounded rationality, bounded willpower and bounded selfishness) characterises humans' decision-making processes as humans and not machines (Thorgeirsson and Kawachi 2013). Investigating associations between economic conditions such as being poor and economic preferences thus becomes crucial in as much as poverty and psychology could be related though not in a simple way (Haushofer and Fehr 2014). In addition, there are claims of socio-economic status influencing cognition and decision-making (Sheehy-Skeffington 2020), assertions contrary to the classical economists' view of rational preference choices (Bruine de Bruin et al. 2020).

Literature on relationships between economic conditions and economic preferences are scanty. Lawrance (1991) reported that poor US households' discount rates were substantially higher than for rich households reflecting impatience among poverty-stricken families. Pender (1996), and Kassie et al. (2008) showed a trend where lower wealth predicted higher behaviourally measured discount rates among Ethiopian farm households and South Indians, respectively. Dohmen et al. (2011) and Guiso and Paiella (2008) reported that wealthier households displayed lower levels of risk aversion suggesting that richer individuals are more willing to assume risk. On the contrary, Bosch-Domènech and Silvestre (2006) concluded that non-wealthy students were more risk loving at higher stakes in an experimental study. Spears (2011) used smaller budget versus larger budget experiments and found that decision-making under difficult trade-offs is likely to consume scarce cognitive resources, such that smaller budget subjects are impaired in tasks that require willpower and self-control. Shah et al. (2015) also observed that decision-making under scarcity - whether the scarcity is temporal, financial or another type, leads to frequent irrational decision-making especially in poverty settings due to attentional capture by salient cues.

The current study aims to establish the relationship between self-reported financial status and economic preferences using experimental data in a developing country setting. The financial situations for many households in developing countries are usually erratic suggesting that the study can shed more light on how individuals make choices under financially stressful or less stressful conditions. Self-reported financial status is a proxy of financial well-being. It is important to know how financial status associates with economic preferences to inform policy meant to address social and economic ills that characterize the poor. In the current study, being 'very broke' (and being broke in general) is positively associated with risk aversion and being 'very broke' is positively associated with impatience. Thus, the results suggest that in times of financial distress, individuals are averse to risks. 'Very broke' subjects exhibit a higher time discount rate on payoffs showing desire to have immediate gratification with a smaller-sooner monetary reward.

The structure of the paper is as follows. The next section provides a description of the experiment. The empirical model section follows. After the empirical model section, next is the results section. Then there is the conclusion and limitations of the study. The data description is provided under the Appendix A. 


\section{Description of the Experiment}

\subsection{Recruitment Strategy}

The sample of this study are university students. An online invite was sent out to all undergraduate university students pursuing Bachelor of Commerce degree programmes at a South African university, using an online learning platform (blackboard) in July 2016. The invitation stated that the experiment was on financial decision-making and that students could freely come and participate. It also stated that when they show up and are ready to participate, they would be eligible for an appearance fee of ZAR50 (equivalent to about US\$3.85). Participants would also stand a chance to win up to ZAR400 (equivalent to about US\$30.79) from the experiment games. The prevailing exchange rate at the time of the experiment was around US\$1 equal to ZAR12.99. The experimental session was about one hour long. The participants thus self-selected into the sample in as much as the experiment was open to all those who showed up from the targeted population of undergraduate Bachelor of Commerce degree programmes students.

Upon arrival, participants received consent form for completion and then shown a sitting place. We used a one-thousand-seater lecture hall. The targeted sample size was 300 participants to allow for physical distancing and privacy when completing experimental tasks. Experimental subjects' enrolment was on first come first serve basis. Two hundred and nineteen (219) students showed up and participated in the study and that is above $70 \%$ of the targeted sample size. Abel et al. (2020) reported a show up of $64 \%$ in their experiment on reference letters in South Africa. Twenty-six participants out of the 219 (i.e., about 11\%) did not complete some important tasks leaving 193 subjects whose data could be analysed. The maximum amount received by an individual was R450 (R400 plus participation fee of R50), the minimum amount received was R50 (i.e., only the participation fee).

\subsection{Experimental Task}

The experimental component of the study consisted of four sets of time preference and four sets of risk preference multiple price list (MPL) tasks (see, Supplementary material 1). The Research Unit in Behavioural Economics and Neuro-economics (RUBEN) at the University of Cape Town in South Africa allowed for use of its MPL tasks in this study. The study adopted a pen and paper approach when completing the experiment tasks. The experimenter read the instructions on what the tasks entail and how to complete. Next, participants completed a practice table for the time preference before they actually completed the four task tables. A typical example of such table is provided as Table 1. In this table, Lottery A represents a constant amount of ZAR250 to be received after a week from the day of the experiment and that is constant for all ten rows. Lottery B, however, shows an increasing amount, by an additional 10\% annual interest rate, down the table from row one up to row ten. Therefore, the participant had a choice of receiving ZAR250 in a week's time or ZAR250 plus a given percentage of interest depending on the row, in a week plus one month. Pay-off time horizons for the four 'time preference' tasks were either after one week or one month and one week; three months and one week; six months and one week; and one year and one week. (Im)patience here is determined by the total number of Lottery A (Lottery B) chosen. Unless a participant is completely impatient, the increments for the amount to be received in a week plus one-month time suggest that at some stage, participants would prefer to wait and receive a larger amount at a later stage. 
Table 1. Typical payoff matrix for the time preference experiments.

\begin{tabular}{ccccc}
\hline & Lottery A & Lottery B & \multicolumn{2}{c}{ Choose A or B } \\
\hline Row & Payment in One Week & Payment in One Month and One Week & & \\
\hline 1 & R250 & R250 + 10\% interest $=$ R252.09 & A & B \\
2 & R250 & R250 + 20\% interest $=$ R254.20 & A & B \\
3 & R250 & R250 + 30\% interest $=$ R256.33 & A & B \\
4 & R250 & R250 + 40\% interest $=$ R258.47 & A & B \\
5 & R250 & R250 + 50\% interest $=$ R260.63 & A & B \\
6 & R250 & R250 + 60\% interest $=$ R262.81 & A & B \\
7 & R250 & R250 + 70\% interest $=$ R265.00 & A & B \\
8 & R250 & R250 + 80\% interest $=$ R267.22 & A & B \\
9 & R250 & R250 + 90\% interest $=$ R269.45 & A & B \\
10 & R250 & R250 + 100\% interest $=$ R271.70 & A & B \\
\hline
\end{tabular}

Similar to time preference tasks, participants completed a practice table for risk preferences with the help of the experimenter. A typical example of risk preference tables is Table 2. Here, Lottery A consists of two monetary amounts that are not very different from each other and are not far apart (e.g., ZAR60 and ZAR50), that are attached to probabilities $(p)$. When the probability of getting ZAR60 increases, the probability of ZAR50 decreases. However, by choosing Lottery A, the participant is opting for safe choices in that the participant gets a sure outcome that is intermediate (not very high or very low: ZAR60 vs ZAR50). However, when choosing Lottery B, which has a similar pattern in terms of changes in probabilities but for amounts that are widely apart (e.g., ZAR100 vs ZAR25), the participant is opting for risky lottery that may give a very high pay-off (ZAR100) or a very low pay-off (ZAR25). The number of safe (risky) choices are determined by the number of Lottery A (Lottery B) selected by the participant in say Table 2. Therefore, each task (in both time and risk preferences category) allowed a subject to make ten choices between two lotteries given as Lottery A or Lottery B (Andersen et al. 2008; Mudzingiri et al. 2019) and each of the 193 subjects completed four tables for risk preference choices and four tables for time preference choices.

Table 2. Typical payoff matrix for the risk preference experiments.

\begin{tabular}{ccccccccccc}
\hline \multicolumn{1}{c}{ Lottery A } & \multicolumn{9}{c}{ Lottery B } \\
\hline Row & $\boldsymbol{p}$ & Rands & $\boldsymbol{p}$ & Rands & $\boldsymbol{p}$ & Rands & $\boldsymbol{p}$ & Rands & Choose A or B \\
\hline 1 & 0.1 & 60 & 0.9 & 50 & 0.1 & 100 & 0.9 & 25 & $\mathrm{~A}$ & $\mathrm{~B}$ \\
2 & 0.2 & 60 & 0.8 & 50 & 0.2 & 100 & 0.8 & 25 & $\mathrm{~A}$ & $\mathrm{~B}$ \\
3 & 0.3 & 60 & 0.7 & 50 & 0.3 & 100 & 0.7 & 25 & $\mathrm{~A}$ & $\mathrm{~B}$ \\
4 & 0.4 & 60 & 0.6 & 50 & 0.4 & 100 & 0.6 & 25 & $\mathrm{~A}$ & $\mathrm{~B}$ \\
5 & 0.5 & 60 & 0.5 & 50 & 0.5 & 100 & 0.5 & 25 & $\mathrm{~A}$ & $\mathrm{~B}$ \\
6 & 0.6 & 60 & 0.4 & 50 & 0.6 & 100 & 0.4 & 25 & $\mathrm{~A}$ & $\mathrm{~B}$ \\
7 & 0.7 & 60 & 0.3 & 50 & 0.7 & 100 & 0.3 & 25 & $\mathrm{~A}$ & $\mathrm{~B}$ \\
8 & 0.8 & 60 & 0.2 & 50 & 0.8 & 100 & 0.2 & 25 & $\mathrm{~A}$ & $\mathrm{~B}$ \\
9 & 0.9 & 60 & 0.1 & 50 & 0.9 & 100 & 0.1 & 25 & $\mathrm{~A}$ & $\mathrm{~B}$ \\
10 & 1 & 60 & 0 & 50 & 1 & 100 & 0 & 25 & $\mathrm{~A}$ & $\mathrm{~B}$ \\
\hline
\end{tabular}

All participants received a ZAR50 show-up fee and in terms of winnings, $10 \%$ of the sample received actual payments. A total of 220 tokens were put in a hat where $10 \%$ (22 tokens) were winning tokens. Subjects were asked to randomly pick tokens from the hat and those who picked the winning tokens were identified. After randomly selecting this $10 \%$ sub-group, we used a within-subject random incentive system (RIS) (Baltussen et al. 2012) to determine each selected subject's winnings and in the following manner. First, we randomly chose between the time preference and the risk preference group of tasks using an eight-sided die, both tasks awarded equal chance. Second, in the event that say the time preference group of tasks is selected, a four-sided die is used to select one out 
of the four tasks. Finally, once a specific task table is selected, a ten-sided die is used to select the row for actual payment from that task table. The payment is determined by the probabilities in that specific row using a ten-sided die for the risk preference tasks. Thus, each selected participant was paid in accordance with the actual choices they made in a given task group and a given task table (Andersen et al. 2008).

\subsection{Financial Literacy Test}

The subjects completed a questionnaire that included thirty questions of financial literacy test. Financial literacy questions were adopted from the Jumpstart, Dollar sense, and National Financial Capability Study (see, Supplementary material 2) (Lusardi and Mitchell 2014; Mandell 2008; LaBorde et al. 2013). The financial literacy variable (which is the financial literacy test score) was measured as a test score from all the questions asked and as a percentage.

\subsection{Ethics}

An ethics approval was granted by the South African university's General Human Ethics Committee where the study took place (UFS-HSD2016/0079) and all the procedures followed in the study were in accordance with the ethical standards of the institutional and the 1964 Declaration of Helsinki and its later amendments.

\section{The Empirical Model}

Two models are estimated here using the extended random effects panel probit regression models to explore the relationships between (i) self-reported financial status (FS) variables and risk preferences, and (ii) self-reported financial status (FS) variables and time preferences. The models closely follow Van Praag (2015) work. The two self-reported financial status variables are coded as binary variables. The variables are coded from the question "how will you describe your financial status?" and the question is answered on a five-point Likert scale with the options "very broke; broke; neither; in good shape, and in very good shape". The first variable compares those that reported to be very broke (an extreme situation) versus other options. Thus, the variable 'financial status: very broke' assumes the value 1 if very broke or 0 otherwise (Models 1 and 2 in Tables 3 and 4). Likewise, the variable 'financial status: broke' assumes the value 1 if the options are very broke/broke, or 0 otherwise (Models 3 and 4 in Tables 3 and 4). As this paper attempts to measure association between self-reported financial status and the economic preferences, the variables for financial status (dummies) are entered as dependent variables in our models because they do not vary by a given game of the economic task. In other words, for the four tables (games) of say risk preferences, the participant's financial status remains constant.

Table 3. Random effects panel probit regression models specifications.

\begin{tabular}{cccc}
\hline Model & Dependent Variable & Independent Variables & Control Variables \\
\hline 1 & $\begin{array}{c}\text { Financial status: very broke } \\
(0 / 1)\end{array}$ & $\begin{array}{c}\text { Time preferences choices } \\
\text { (impatience) }\end{array}$ & $\begin{array}{c}\text { Financial literacy; amount held as cash or in } \\
\text { bank account; gender; age; location; game }\end{array}$ \\
\hline 2 & $\begin{array}{c}\text { Financial status: very broke } \\
(0 / 1)\end{array}$ & $\begin{array}{c}\text { Risk preference choices (risk } \\
\text { aversion) }\end{array}$ & $\begin{array}{c}\text { Financial literacy; amount held as cash or in } \\
\text { bank account; gender; age; location; game }\end{array}$ \\
\hline 3 & Financial status: broke $(0 / 1)$ & $\begin{array}{c}\text { Time preferences choices } \\
\text { (impatience) }\end{array}$ & $\begin{array}{c}\text { Financial literacy; amount held as cash or in } \\
\text { bank account; gender; age; location; game }\end{array}$ \\
\hline 4 & Financial status: broke $(0 / 1)$ & $\begin{array}{c}\text { Risk preference choices (risk } \\
\text { aversion) }\end{array}$ & $\begin{array}{c}\text { Financial literacy; amount held as cash or in } \\
\text { bank account; gender; age; location; game }\end{array}$ \\
\hline
\end{tabular}


Table 4. Self-reported financial status and its association with economic preferences.

\begin{tabular}{|c|c|c|c|c|}
\hline & \multicolumn{2}{|c|}{ Financial Status I: Very Broke } & \multicolumn{2}{|c|}{ Financial Status II: Broke } \\
\hline & Model 1 & Model 2 & Model 3 & Model 4 \\
\hline$\Delta$ Risk aversion & & $\begin{array}{l}0.0021 \\
(0.031)\end{array}$ & & $\begin{array}{c}-0.0059 \\
(0.024)\end{array}$ \\
\hline Mean: Risk aversion & & $\begin{array}{l}0.069^{* * *} \\
(0.005)\end{array}$ & & $\begin{array}{c}0.023^{* * *} \\
(0.005)\end{array}$ \\
\hline$\Delta$ Impatience & $\begin{array}{c}0.012 \\
(0.011) \\
\end{array}$ & & $\begin{array}{c}-0.0036 \\
(0.009)\end{array}$ & \\
\hline Mean: Impatience & $\begin{array}{c}0.075^{* * *} \\
(0.017)\end{array}$ & & $\begin{array}{l}-0.040 \\
(0.035)\end{array}$ & \\
\hline Financial literacy & $\begin{array}{c}-0.084^{* * *} \\
(0.001)\end{array}$ & $\begin{array}{c}-0.084^{* * *} \\
(0.000)\end{array}$ & $\begin{array}{c}0.0085^{* * * *} \\
(0.000)\end{array}$ & $\begin{array}{l}0.0076^{* * *} \\
(0.000)\end{array}$ \\
\hline $\begin{array}{l}\text { Ln (amount held in } \\
\text { Rand) }\end{array}$ & $\begin{array}{l}-0.13^{* * *} \\
(0.003)\end{array}$ & $\begin{array}{l}-0.14^{* * *} \\
(0.000)\end{array}$ & $\begin{array}{c}-0.16^{* * *} \\
(0.004)\end{array}$ & $\begin{array}{c}-0.16^{* * *} \\
(0.000)\end{array}$ \\
\hline Female & $\begin{array}{l}-0.13^{* * *} \\
(0.007)\end{array}$ & $\begin{array}{l}-0.15^{* * *} \\
(0.005)\end{array}$ & $\begin{array}{l}-0.21^{* * *} \\
(0.005)\end{array}$ & $\begin{array}{c}-0.23^{* * *} \\
(0.004)\end{array}$ \\
\hline Age & $\begin{array}{c}-0.079 * * * \\
(0.003)\end{array}$ & $\begin{array}{c}-0.083^{* * *} \\
(0.001)\end{array}$ & $\begin{array}{c}0.027^{* * *} \\
(0.001)\end{array}$ & $\begin{array}{c}0.021^{* * *} \\
(0.001)\end{array}$ \\
\hline Urban & $\begin{array}{c}-0.28 * * * \\
(0.007)\end{array}$ & $\begin{array}{c}-0.28^{* * *} \\
(0.004)\end{array}$ & $\begin{array}{c}-0.15^{* * *} \\
(0.005)\end{array}$ & $\begin{array}{l}-0.13^{* * *} \\
(0.003)\end{array}$ \\
\hline Game 2 (time/risk) & $\begin{array}{c}0.026^{* * *} \\
(0.006)\end{array}$ & $\begin{array}{c}0.00040 \\
(0.004)\end{array}$ & $\begin{array}{l}-0.017 \\
(0.014)\end{array}$ & $\begin{array}{c}-0.00061 \\
(0.003)\end{array}$ \\
\hline Game 3 (time/risk) & $\begin{array}{c}0.023 * * * \\
(0.005)\end{array}$ & $\begin{array}{l}0.0029 \\
(0.007) \\
\end{array}$ & $\begin{array}{l}-0.013 \\
(0.011)\end{array}$ & $\begin{array}{l}0.0026 \\
(0.004)\end{array}$ \\
\hline Game 4 (time /risk) & $\begin{array}{c}0.023^{* * *} \\
(0.005)\end{array}$ & $\begin{array}{c}0.0033^{* *} \\
(0.002)\end{array}$ & $\begin{array}{l}-0.014 \\
(0.012)\end{array}$ & $\begin{array}{l}0.0017^{* * *} \\
(0.000)\end{array}$ \\
\hline Constant & $\begin{array}{l}2.11^{* * *} \\
(0.082)\end{array}$ & $\begin{array}{l}2.39 * * * \\
(0.004)\end{array}$ & $\begin{array}{l}0.63^{* * *} \\
(0.239)\end{array}$ & $\begin{array}{l}0.41^{* * *} \\
(0.008)\end{array}$ \\
\hline$N$ & 756 & 756 & 756 & 756 \\
\hline
\end{tabular}

Notes: Standard errors in parentheses; ${ }^{*} p<0.10,{ }^{* *} p<0.05,{ }^{* * *} p<0.01$.

The two main independent variables that are entered in separate models are the risk preference and the time preference. The measure for time preference i.e., (im)patience, is elicited from four task tables for time preference. When Lottery A is chosen in a row (smaller sooner), that is counted as an impatient choice and when Lottery B is chosen (larger later), that is counted as a patient choice. The measure 'impatience' is thus a discrete variable ranging from 0 (when no Lottery A is chosen) and 10 (when Lottery A is chosen for all rows in a given task). In other words, the more the number of Lottery A chosen, the more impatient the subject is. For each participant, impatience is measured across the four tasks such that impatience ${ }_{i j}$ refers to the level of impatience for subject ' $i$ ' in task table (game) ' $\mathrm{j}$ '.

The measure for risk preference, i.e., risk aversion, the second covariate of direct interest, is obtained from the task tables (games) for risk preference. When Lottery A is chosen in a row in this set of tasks, that is counted as 'risk averse' choice and when Lottery B is chosen, that is counted as a risk loving choice. The measure 'risk aversion' is, therefore, a discrete variable that increases with the number of Lottery A choices made. So, risk_aversion ${ }_{\mathrm{ij}}$ refers to the level of risk aversion for subject ' $i$ ' in task table ' $j$ '. The four task tables per subject per given economic preference (time or risk) allow for application of panel data analysis in this study and following Van Praag (2015) panel probit approach. 
Van Praag (2015) argues that contrary to the existing literature (Cameron and Trivedi 2010) which states that the within estimator can only be determined by regressing on the differences, regressing on the original observation in the extended model, gives the same estimates. Hence, the extended model ensures that a probit model can be used to estimate qualitative panel equations, an appropriate approach in the current study. Following Van Praag (2015) closely, both deviations from the mean ( $\Delta$ risk aversion $/ \Delta$ impatience) and the averages over time (mean risk aversion/ mean impatience) were included in the models. Finally, financial literacy, amount held in bank account or as cash equivalent (in natural logarithms), gender (female), age, geographical location of subjects (urban) and game (with values 1 to 4 ) are included as controls in the models.

Studies such as Bellemare and Shearer (2010), Drichoutis and Lusk (2016), Eckel and Wilson (2004) used the number of safe choices while Bellemare and Shearer (2010) and Drichoutis and Lusk (2016) used the number of impatient choices to measure risk aversion and impatience respectively. Our current study follows same approaches in terms of measurement of economic preferences. Table 3 outlines the specifications of the estimated random effect panel probit regression models. A Hausman test and a Breusch-PaganLagrangian multiplier test for random effects favours the use of the random effect panel model ahead of the fixed effect panel model.

\section{Results}

The descriptive results for the study sample are presented in (Appendix A) of our paper. The Appendix A section gives a summary of the data in form of some measures of central tendencies and measures of dispersion. The section also provides histograms and correlations for selected key variables. Here, we present and discuss regression results (Table 4). Models 1 and 2 in Table 4 show that both impatience $(\beta=0.075 ; p=0.017)$ and risk aversion $(\beta=0.069 ; p<0.05)$ associates positively with a financial situation of being 'very broke'. The more the average number of impatient choices that are selected by the participant, the more likely the participant is in a distressed financial status 'very broke'. Similarly, the more the average number of safe choices that are selected by the participant the more likely the participant will report a distressed financial status. The fact that 'very broke' situation statistically significantly associates with both impatience and risk aversion could be revealing the financial constraints faced by the financially distressed participants. These financial constraints necessitate opting for safe and low paying choices and settling for smaller-sooner and immediate gratification in order to mitigate the stressful financial condition faced by the subjects. These results are similar to Mani et al. (2013) who reported that people with low income or who are in poverty have a high discount rate to payoffs and are risk averse. Jachimowicz et al. (2017) reported that the immediate financial needs could be the reason for impatience and risk aversion in economic experiments.

Model 4 in Table 4 shows that a financial situation of being 'broke' associates positively with risk aversion $(\beta=0.023 ; p=0.005)$. This positive association is similar to one reported for the extreme situation of being very broke although the 'broke' analysis has a smaller coefficient. The results show that financial situation induces subjects to be more cautious about their risk choices. Our results are similar to Dohmen et al. (2011) and Guiso and Paiella (2008) who concluded that individuals with low income are more risk averse but contradict results by Bosch-Domènech and Silvestre (2006) who found out that low income students reveal risk loving behaviour.

However, there is no significant association between being broke and impatience (model 3). Thus, the extent of financial distress matters when intertemporal decisions are made. In the current study, comparing those on the negative extreme side of the financial scale as measured by self-financial status reporting, shows that impatience matter. However, relaxing this stringent categorisation such that those that are broke (mild negative financial status) are grouped together with the very broke, show that impatience is insignificant. Nevertheless, risk aversion is statistically significant even as we relax the stringent categorisation. There is some consistence with the risk aversion results. 
There are also some results for control variables worth discussing here. The study shows in both Models 1 and 2 that the lower the level of financial literacy, the more likely the participant is to report that they are 'very broke'. However, when applying relaxed categorisation, when financial literacy improves, the likelihood of being broke increases too as shown by Models 3 and 4. As one would expect, participants that reported higher values of money held in the account or as cash were less likely to report that they were in a 'very broke' or 'broke' financial status. In addition, female participants and urban dwellers were associated with being less likely to report that they are 'very broke or broke'.

Risk preference and time preference choices play an important role in every person's life. These preferences influence economic agents' various activities such as saving, consumption and investment decisions (Angrisani et al. 2020). Association of these preferences with situations that economic agents find themselves in, is equally crucial. Angrisani et al. (2020) emphasised the importance of assessing whether risk preferences are stable individual characteristics that are not affected by economic and social conditions among other factors. The notion that individuals are always rational when they make decisions has gradually lost its truthfulness. In reality, psychological biases, bounded rationality, bounded willpower and bounded selfishness play a vital role in shaping preference choices of individuals. Exploring the relationship between financial status and the time and risk preference choices can provide information on whether biasedness in choices exist or not, under different financial circumstances. Financial status could be related to personality traits and emotions such as fear, loss aversion, self-control, confidence, anger, hope and sadness among other factors (Aren and Hamamci 2020). Evidence also show that overconfidence bias and self-control bias are positively related with risk preference while loss aversion bias and regret aversion bias are negatively related with risk preferences (Ritika and Nawal Kishor 2020).

Subjects that are in extreme financial stress (very broke), are substantially risk averse and they are impatient. Their behaviour shows aspects of bounded rationality and bounded willpower. The fact that the option 'very broke' was chosen by those subjects who also selected more safe choices reveals that such subjects' circumstances induced loss aversion bias, a trait of bounded rationality. On the other hand, being present-biased and settling for higher impatient choices resonate well with bounded willpower where subjects value present gratification (smaller-sooner payoffs) at the expense larger-later payoffs. A US study survey on households before and after payday concluded that being liquidity constrained induced present biasedness in the households (Carvalho et al. 2016). In addition, poor people tend to invest in low return investments and their business ventures are usually small with no economies of scale (Haushofer and Fehr 2014). For the current experimental subjects, participation in these experiments where they stand to win some money is an opportunity that cannot be spilled. They opt for safe choices in that it guarantees an outcome although it is intermediate in magnitude (not very high or very low: ZAR60 vs ZAR50) as opposed to amounts that are widely apart (e.g., ZAR100 vs. ZAR25). Similarly, for the delayed choices, their financial stress situation associates with choosing immediate and lower payoffs.

Relaxing strict categorisation such that the 'very broke' and 'broke' subjects are put in one category watered down the impatience attitude. However, the grouped subjects still exhibited a significant risk aversion attitude. The current study's results also reveal the importance of the relationship between financial status and the economic preferences in support of Amir et al. (2020) findings that risk and time preferences are environmentally flexible.

\section{Conclusions}

This study investigated the association between self-reported financial status and economic preferences in a developing country setting and using data from an incentivised experiment and a survey. Data collection process also included the use of financial literacy assessment task. The study contributes to literature on interlinkages between temporal 
poverty and decision-making processes under risky and intertemporal situations. The current study has some limitations worth highlighting. First, when subjects self-select into an experiment sample, the sample may characterise subjects with the same characteristics. Subjects that find it necessary to commit their time to that experiment for a certain and common reason. As a result, the sample may have biasedness with respect to that characteristic. In this case, since the experiment involves winning money, there is a possibility that those that are financially in need may show up. Of course, this study sent out an open invitation to all Bachelor of Commerce degree students with the hope to raise the response rate. A proper random sampling strategy may be necessary to minimise this problem. Second, intertemporal choices involving money depend on inflation rate especially as the period gets longer. That would need a good grasp of how interest rates work and the prevailing inflation rates in that context for the participants to establish how worthily it is to wait for a larger payoff. The financial literacy level among our subjects is quite low and so their level of understanding of inflation is questionable. However, the increase of interest rates up to $100 \%$ in the last row of the time preference tasks completed in an economy with an average inflation between $3-6 \%$ ensured that inflation problem was taken care of. Last, the question "how will you describe your financial situation today?" is quite narrow and so the measurement of self-reported financial status is not strong. Scripts that measure financial status over a reasonable period such as a month and not just for a specific day can be more useful.

Nevertheless, the study contributes to an understanding of how people make decisions which involve some degree of uncertainty and sometimes requiring thinking at the margins and that is particularly important in so far as decisions on investments, education, personal health, and other welfare-enhancing activities have such features. Socio-economic statuses play a critical role in decision-making processes that have long lasting life effects too. In the current study, self-reported financial status acts as a proxy for temporal poverty. The study established a positive association between bad financial status (both very broke and broke) and risk aversion behaviour on one hand, and a positive association between extreme financial stresses (very broke) and impatience. Such a finding illustrates the importance of psychology of poverty on economic preferences and in decision-making in general, even as poverty is temporary as represented by self-reported financial status.

Supplementary Materials: The followings are available online at https:/ / www.mdpi.com/article/ $10.3390 / j r f m 14060243 /$ s1, Supplementary material, S1: Experiment Instrument; Supplementary material, S2: Financial Literacy Questionnaire.

Author Contributions: Conceptualization: C.M., S.G. and C.G.; methodology: S.G., C.M. and C.G.; software: C.M. and C.G.; validation: C.G. and S.G.; formal analysis: C.M., S.G. and C.G.; investigation: C.M.; writing—original draft preparation: S.G.; writing—review and editing: C.G., S.G. and C.M. All authors have read and agreed to the published version of the manuscript.

Funding: This research received no external funding. The researchers used their institution's (University of the Free State) research funds for data collection and running of experiments as well as the APC.

Institutional Review Board Statement: The study was conducted according to the guidelines of the Declaration of Helsinki, and approved by the University of the Free State's General Human Research Ethics Committee. Approval No.: UFS-HSD2016/0079.

Informed Consent Statement: Informed consent was obtained from all subjects in the study.

Data Availability Statement: Data is available from authors upon request.

Acknowledgments: The authors acknowledge the Research Unit in Behavioural Economics and Neuro-economics (RUBEN) at the University of Cape Town in South Africa for the use of its MPL tasks in this study.

Conflicts of Interest: There are no conflicts of interest. 


\section{Appendix A. Data Appendix}

This Data Appendix section provides descriptive statistics, univariate graphical illustrations of the distributions and correlations for key variables in our sample. As shown in Table A1, the average age for the participants is 22.22 years and participants had on average, ZAR1490 held in their accounts and/or in form of cash. The average number of safe choices and impatient choices are close to the mid-mark of 5 . Within a range of 1 to 5 where 1 means that a participant is very broke and 5 means that the participant is in very good shape financially [see notes under Figure A1], an average (median) value of 2.5 (2) suggesting rightward skewness. The average financial literacy for the experiment subjects is generally low at $40 \%$.

Table A1. Descriptive statistics.

\begin{tabular}{ccccc}
\hline Variable & Mean & Standard Deviation & 95\% Confidence Interval & Sample (n) \\
\hline Age (years) & 22.22 & 0.12 & $22.04-22.50$ & 193 \\
Rand amount held (ZAR) & 1490.11 & 241.17 & $1016.68-1963.55$ & 193 \\
Safe choices (risk aversion) & 4.62 & 0.08 & $4.46-4.79$ & 772 \\
Impatient choices & 5.97 & 0.11 & $5.74-6.19$ & 772 \\
Financial literacy score (\%) & 40.05 & 0.04 & $38.90-41.20$ & 193 \\
Very broke & 0.18 & 0.01 & $0.14-0.20$ & 772 \\
Broke & 0.52 & 0.02 & $0.49-0.56$ & 772 \\
Female & 0.53 & 0.02 & $0.49-0.56$ & 193 \\
Urban & 0.69 & 0.02 & $0.65-0.72$ & 193 \\
\hline
\end{tabular}

Notes: two decimals rounded upwards.

To elucidate more on the distribution of the key variables in the study, we provide simple histograms for four key variables. Evidence illustrated in Figure A1 show that less than $2 \%$ of the subjects reported to be in very good shape financially while about one in five felt that they were in good shape. However, $17.62 \%$ were very broke, more than a third of the sample $(34.72 \%)$ reported that they were broke while $27.46 \%$ were breaking-even (neither broke nor in good shape) [upper left panel]. This distribution relates well to low bank $/$ cash amounts reported by the subjects (mean $=$ ZAR1490; median $=$ ZAR250) as shown in Table A1. The upper right panel of Figure A1 illustrates that the scores of the subjects with respect to financial literacy test is positively skewed and has a median mark of $36 \%$ and mean mark of $40 \%$, and that is quite low for Bachelor of Commerce students at a university. As shown by the time preference panel, above $25 \%$ of the subjects were highly impatient as shown by making a maximum of ten present biased choices. However, in general the number of time preference choices show some kind of normal distribution [lower left panel]. Similar trend of normal distribution is shown for the number of risk preference or safe choices [lower right panel].

The correlation statistics of self-reported financial status and covariates considered in the study are summarised in Table A2. Impatience and risk aversion are significantly negatively correlated with self-reported financial status suggesting the importance of economic preferences in financial management decisions by university students. Financial literacy and the rand amount held in bank account or as cash are, as expected, significantly positively correlated with self-reported financial status. Being female and residing in an urban area are also positively and significantly correlated with self-reported financial status. 

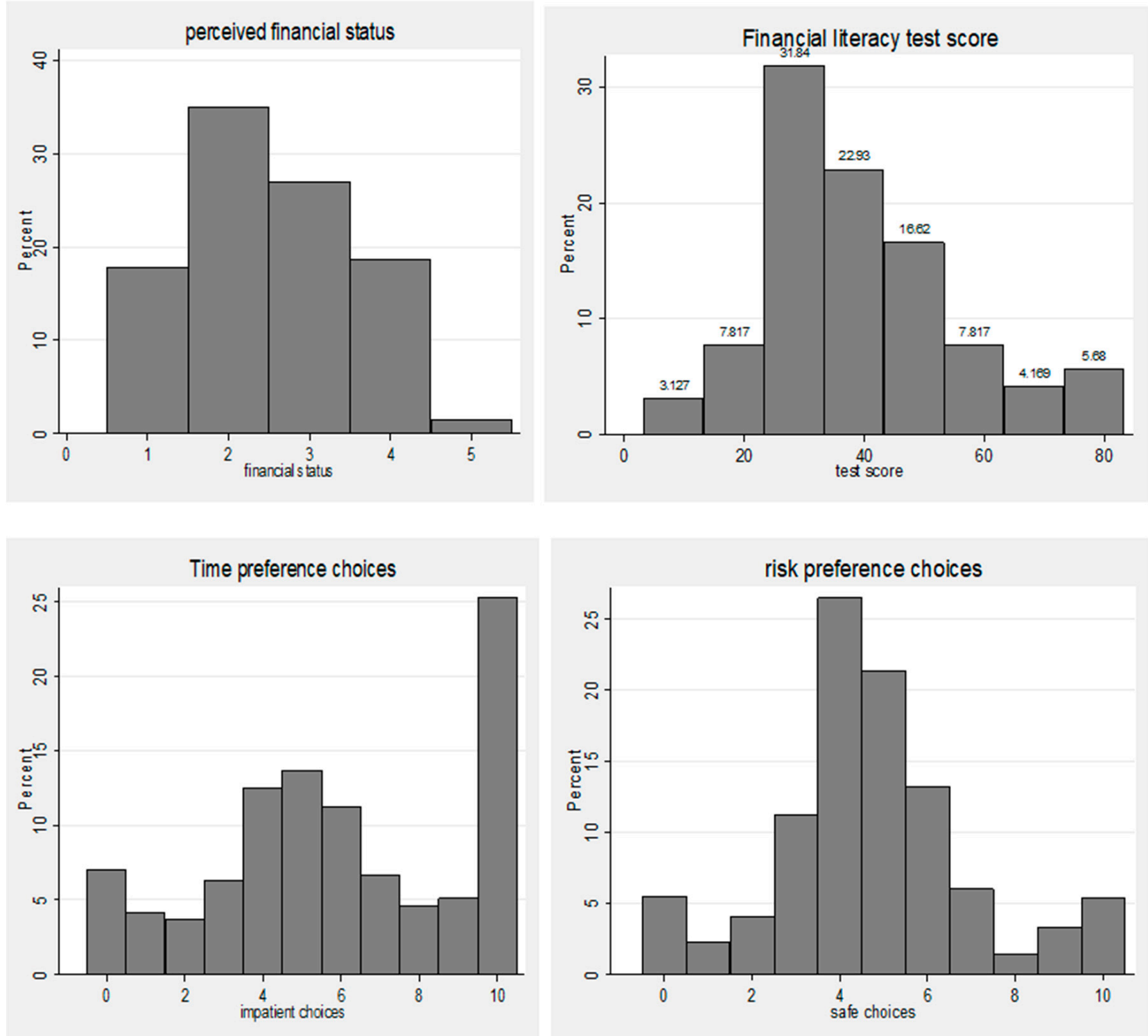

Figure A1. Self-reported financial status, financial literacy test scores and economic preference choices. Notes: for the self-reported financial status: value $1=$ very broke; $2=$ broke; $3=$ neither; $4=$ in good shape, and $5=$ in very good shape.

Table A2. Correlation between self-reported financial status and covariates.

\begin{tabular}{cccccc}
\hline Covariate & $\begin{array}{c}\text { Partial } \\
\text { Correlation }\end{array}$ & $\begin{array}{c}\text { Semi-Partial } \\
\text { Correlation }\end{array}$ & $\begin{array}{c}\text { Partial Correlation } \\
\text { Squared }\end{array}$ & $\begin{array}{c}\text { Semi-Partial } \\
\text { Correlation Squared }\end{array}$ & $p$-Value \\
\hline Financial literacy & 0.1648 & 0.1619 & 0.0272 & 0.0262 & 0.0000 \\
Impatience & -0.0327 & -0.0317 & 0.0011 & 0.001 & 0.0001 \\
Risk aversion & -0.036 & -0.0349 & 0.0013 & 0.0012 & 0.0000 \\
Gender (female) & 0.0768 & 0.0746 & 0.0059 & 0.0000 & 0.0000 \\
Age & 0.0017 & 0.0017 & 0.0000 & 0.0004 & 0.0362 \\
Location (urban) & 0.0214 & 0.0207 & 0.0005 & 0.0177 & 0.0000 \\
Rand Amount held & 0.1361 & 0.1331 & 0.0185 & 0 \\
\hline
\end{tabular}

\section{References}

Abel, Martin, Rulof Burger, and Patrizio Piraino. 2020. The value of reference letters: Experimental evidence from South Africa. American Economic Journal: Applied Economics 12: 40-71. [CrossRef]

Alan, Sule, Seda Ertac, Elif Kubilay, and Gyongyi Loranth. 2020. Understanding gender differences in leadership. The Economic Journal 130: 263-89. [CrossRef] 
Amir, Dorsa, Matthew R. Jordan, Katherine Mcauliffe, Claudia R. Valeggia, Lawrence S. Sugiyama, Richard G. Bribiescas, J. Josh Snodgrass, and Yarrow Dunham. 2020. The developmental origins of risk and time preferences across diverse societies. Journal of Experimental Psychology: General 149: 650-61. [CrossRef]

Andersen, Steffen, Glenn W. Harrison, Morten I. Lau, and E. Elisabet Rutström. 2008. Eliciting risk and time preferences. Econometrica 76: 583-618. [CrossRef]

Andreoni, James, Amalia Di Girolamo, John A. List, Claire Mackevicius, and Anya Samek. 2020. Risk preferences of children and adolescents in relation to gender, cognitive skills, soft skills, and executive functions. Journal of Economic Behavior and Organization 179: 729-42. [CrossRef]

Angrisani, Marco, Marco Cipriani, Antonio Guarino, Ryan Kendall, and Julen Ortiz de Zarate. 2020. Risk Preferences at the Time of COVID-19: An Experiment with Professional Traders and Students. Available online: https://papers.ssrn.com/sol3/papers.cfm? abstract_id=3674884 (accessed on 17 March 2021).

Aren, Selim, and Hatice Nayman Hamamci. 2020. Relationship between risk aversion, risky investment intention, investment choices: Impact of personality traits and emotion. Kybernetes 49: 2651-82. [CrossRef]

Baltussen, Guido, G. Thierry Post, Martijn J. Van Den Assem, and Peter P. Wakke. 2012. Random incentive systems in a dynamic choice experiment. Experimental Economics 15: 418-43. [CrossRef]

Bangs, Joann. 2009. Thinking on the Margin: A Classroom Experiment. American Journal of Business Education, 2. Available online: https:/ / clutejournals.com/index.php/AJBE/article/download/4040/4093 (accessed on 18 August 2020). [CrossRef]

Bellemare, Charles, and Bruce Shearer. 2010. Sorting, incentives and risk preferences: Evidence from a field experiment. Economics Letters 108: 345-48. [CrossRef]

Bertrand, Marianne. 2011. New Perspectives on Gender. Handbook of Labor Economics. Amsterdam: Elsevier, vol. 4. [CrossRef]

Bertrand, Marianne, Sendhil Mullainathan, and Eldar Shafir. 2004. A behavioral-economics view of poverty. American Economic Review 94: 419-23. [CrossRef]

Bosch-Domènech, Antoni, and Joaquim Silvestre. 2006. Do the Wealthy Risk More Money? An Experimental Comparison. In Institutions, Equilibria and Efficiency. Copenhagen: Springer, pp. 95-116. [CrossRef]

Bruine de Bruin, Wändi, Andrew M. Parker, and Baruch Fischhoff. 2020. Decision-Making Competence: More Than Intelligence? Current Directions in Psychological Science 29: 186-92. [CrossRef]

Cameron, Adrian Colin, and Pravin K. Trivedi. 2010. Microeconometrics Using Stata. Microeconometrics. College Station: Stata Press, vol. 2.

Carvalho, Leandro S., Stephan Meier, and Stephanie W. Wang. 2016. Poverty and Economic Decision-Making: Evidence from Changes in Financial Resources at Payday. American Economic Review 106: 260-84. [CrossRef] [PubMed]

Cohen, Jonathan, Keith Marzilli Ericson, David Laibson, and John Myles White. 2020. Measuring time preferences. Journal of Economic Literature 58: 299-347. [CrossRef]

Dohmen, Thomas, Armin Falk, David Huffman, Uwe Sunde, Jürgen Schupp, and Gert G. Wagner. 2011. Individual risk attitudes: Measurement, determinants, and behavioral consequences. Journal of the European Economic Association 9: 522-50. [CrossRef]

Drichoutis, Andreas C., and Jayson L. Lusk. 2016. What can multiple price lists really tell us about risk preferences? Journal of Risk and Uncertainty 53: 89-106. [CrossRef]

Eckel, C. Catherine, and Rick K. Wilson. 2004. Is trust a risky decision? Journal of Economic Behavior and Organization 55: 447-65. [CrossRef]

Guiso, Luigi, and Monica Paiella. 2008. Risk Aversion, Wealth, and Background Risk. Journal of the European Economic Association 6: 1109-50. [CrossRef]

Haushofer, Johannes, and Ernst Fehr. 2014. On the psychology of poverty. Science 344: 862-67. [CrossRef] [PubMed]

Insler, Michael, James Compton, and Pamela Schmitt. 2016. The investment decisions of young adults under relaxed borrowing constraints. Journal of Behavioral and Experimental Economics 64: 106-21. [CrossRef]

Jachimowicz, Jon M., Salah Chafik, Sabeth Munrat, Jaideep C. Prabhu, and Elke U. Weber. 2017. Community trust reduces myopic decisions of low-income individuals. Proceedings of the National Academy of Sciences 114: 5401-6. [CrossRef]

Kassie, Menale, John Pender, Mahmud Yesuf, Gunnar Kohlin, Randy Bluffstone, and Elias Mulugeta. 2008. Estimating returns to soil conservation adoption in the northern Ethiopian highlands. Agricultural Economics 38: 213-32. [CrossRef]

LaBorde, Pamela M., Sandra Mottner, and Pamela Whalley. 2013. Personal Financial Literacy : Perceptions of Knowledge, Actual Knowledge and Behavior of College Students. Journal of Financial Education 39: 1-31. [CrossRef]

Lawrance, Emily C. 1991. Poverty and the Rate of Time Preference: Evidence from Panel Data. Journal of Political Economy 99: 54-77. [CrossRef]

Lusardi, Annamaria, and Olivia S. Mitchell. 2014. The economic importance of financial literacy: Theory and evidence. Journal of Economic Literature 52: 5-44. [CrossRef] [PubMed]

Mandell, Lewis. 2008. Financial Education in High School. In Overcoming the Saving Slump: How to Increase the Effectiveness of Inancial Education and Saving Programs. Edited by Annamaria Lusardi. Chicago: University of Chicago Press, pp. $257-79$.

Mani, Anandi, Sendhil Mullainathan, Eldar Shafir, and Jiaying Zhao. 2013. Poverty Impedes Cognitive Function. Science 341: 976-80. [CrossRef]

Mudzingiri, Calvin, John W. Muteba Mwamba, Jacobus Nicolaas Keyser, and Alex Bara. 2019. Indecisiveness on risk preference and time preference choices. Does financial literacy matter? Cogent Psychology, 6. [CrossRef] 
Mullainathan, Sendhil, and Eldar Shafir. 2013. Decision making and policy in the context of poverty. In Behavioral Foundations of Public Policy. Edited by Eldar Shafir. Princeton: Princeton University Press, pp. 281-300.

Pender, John L. 1996. Discount rates and credit markets: Theory and evidence from rural India. Journal of Development Economics 50: 257-96. [CrossRef]

Ravallion, Martin. 2012. Fighting poverty one experiment at a time: A review of abhijit banerjee and esther duflo's poor economics: A radical rethinking of the way to fight global poverty. Journal of Economic Literature. [CrossRef]

Ritika and Nawal Kishor. 2020. Risk preferences for financial decisions: Do emotional biases matter? Journal of Public Affairs. [CrossRef]

Shah, Anuj K., Eldar Shafir, and Sendhil Mullainathan. 2015. Scarcity Frames Value. Psychological Science 26: 402-12. [CrossRef]

Sheehy-Skeffington, Jennifer. 2020. The effects of low socioeconomic status on decision-making processes. Current Opinion in Psychology 33: 183-88. [CrossRef]

Spears, Dean. 2011. Economic decision-making in poverty depletes behavioral control. B.E. Journal of Economic Analysis and Policy, 11. [CrossRef]

Sutter, Matthias, Claudia Zoller, and Daniela Glätzle-Rützler. 2019. Economic behavior of children and adolescents—A first survey of experimental economics results. European Economic Review 111: 98-121. [CrossRef]

Thorgeirsson, Tryggvi, and Ichiro Kawachi. 2013. Behavioral economics: Merging psychology and economics for lifestyle interventions. American Journal of Preventive Medicine. [CrossRef] [PubMed]

Van Praag, Bernard M.S. 2015. A New View on Panel Econometrics: Is Probit Feasible after All? (No. 9345). IZA Discussion Paper. Amsterdam: IZA Instute of Labour Economics. Available online: https:/ / papers.ssrn.com/sol3/papers.cfm?abstract_id=2663775 (accessed on 10 July 2020). 